\section{Rounding up plant cells}

\section{Sergio J. Ochatt and Anne Moessner INRA, UMR LEG, Dijon, France}

\begin{abstract}
Compared to animal cells, plant cells are typically non-spherical, which may bias morphometric and fluorimetric analyses, including flow cytometry and other approaches used in the study of cellular biodiversity. The morphometric study of cotyledonary cells may serve to distinguish between genotypes, as cell shape is clearly an important issue when assessing flour quality and seed digestibility by animals, being affected by the surface and volume of particles. We devised a shape coefficient that resolves these difficulties with pea (Pisum sativum $L$.), and may find general applicability in cytological studies and for the characterization of biodiversity patterns.
\end{abstract}

\section{Introduction}

Using plant protein as animal feed, fodder or human food represents a strategic choice. Grain legumes are a source of high-quality protein for human consumption (e.g. beans, lentils, peas, chickpeas, faba beans) ${ }^{1}$ and animal feed as seeds (e.g. peas, horse beans, soybeans, lupins) ${ }^{2}$ or fodder (e.g. alfalfa, clover). Legumes have historically been utilized mainly as whole seeds but in recent years, interest has grown in their use in other forms (e.g. flour, concentrate, isolate). Pea (Pisum sativum $L$.) seed proteins are particularly rich in lysine and have a starch content close to cereals and a nitrogen content intermediate between soybean and cereals. Therefore, adding pea to industrial feed formulations is of relevance for pigs, ruminants and poultry. Given the differences between the digestion of feed by ruminants and monogastrics, ${ }^{3}$ it is important to distinguish flours and grains that are adapted for either group of animals. This is particularly important in terms of particle size, ${ }^{4}$ primary cell wall content ${ }^{5}$ and biomechanical properties ${ }^{6}$ which influence feed digestibility. However, in pea, published information on the final size (weight) of seeds ${ }^{7,8}$ and on the size and characteristics of cotyledonary cells ${ }^{9}$ is scant. In a previous study with 35 pea genotypes, Roche et al. determined the morphometry (number, surface, volume) and the wall thickness of cotyledonary cells isolated enzymatically (with Pectinase, see below) from mature seeds without affecting their shape, and were able to group the genotypes into different classes according to these parameters. ${ }^{10}$ Interestingly, we verified several differences in the ranking of genotypes analyzed either in terms of their belonging to a particular class or within a same class of size. These differences, which concerned surface versus volume of cells, might be ascribed to the cell shape, and prompted the studies described here, where the main goal was to devise a reliable and robust shape coefficient (SC).

\section{Materials and Methods}

Pea (Pisum sativum L.) genotypes D 265, RIL156, Ballet, Princess and V380 were studied. Ground seeds were weighed and disinfected (ethanol 70\% for $1 \mathrm{~min}$, then $\mathrm{NaOCl}$ [ $2 \%$ active $\mathrm{Cl}_{2}$ ] for $15 \mathrm{~min}$, with three sterile milliQ water rinses) and, in order to disaggregate the ground particles, three different treatments without any observable effect on cell shape were applied: i) T, no treatment at all; ii) $\mathrm{H}$, an acid hydrolysis $\left(\mathrm{HCl} 1 \mathrm{M}\right.$, at $60^{\circ} \mathrm{C}$, for $45 \mathrm{~min}$ ); iii) $\mathrm{H}+\mathrm{P}$, the same acid hydrolysis followed by an enzymatic treatment as used to digest cotyledons (Pectinase 1\% [w/v] dissolved in $0.2 \mathrm{M}$ sodium acetate buffer plus $0.2 \mathrm{M} \mathrm{D}$-sorbitol, pH 5.5, at $37^{\circ} \mathrm{C}$, with gentle shaking, for $2 \mathrm{~h}$ ).

Given the very large number of measurements taken for each genotype, only one grinding grid was used ( $3 \mathrm{~mm}$ size) and particles recovered from 125,160 and $200 \mu \mathrm{m}$ sieving were analyzed.

The above preparations were used to study cell surface characteristics using Calcofluor White-stained cells using UV microscopically. ${ }^{11}$ Microscopic observation of slides (2-D) was facilitated by this stain that labels cellulose by covalent binding at the $\beta 1-4$ bonds of the cellulose molecule. The fluorescence can then be measured and cell surface dimensions determined using image acquisition programmes (ArchimedPlus and Histolab, Microvision, France). ${ }^{4}$

Cell volume was determined in 3-D by using a Multisizer II Coulter (EPICs) granulometric densitometer. This apparatus transforms the objects counted in a sphere, and determines their volume as the volume displaced following Archimedes principle. Hence, microscopically, the true shape of cells is assessed but only in 2-D, while with the microdensitometer above their 3-D image is considered.

A shape coefficient was devised and used in the characterization of the five tested pea genotypes, which were also analyzed for the same morphometric traits after seed grinding. This shape coefficient (SC) was calculated as:

$$
\mathrm{SC}=\frac{\sqrt{\mathrm{a}^{2}-\mathrm{b}^{2}}}{\mathrm{a}}
$$

Correspondence: Sergio J. Ochatt, INRA, UMR LEG, B.P. 86510, F-21000 Dijon, France.

E-mail: ochatt@dijon.inra.fr

Key words: calcofluor white, cell surface, cell volume, densitometry, pea seeds, shape coefficient

Contributions: I hereby declare, on behalf of myself and my co-author, that the article submitted is an original work and has neither been published in any other peer-reviewed journal nor is under consideration for publication by any other journal. The article does not contravene any existing copyright or any other third party rights. These statements are based on the International Committee of Medical Journals Editors criteria.

Conflict of interest: the authors report no conflicts of interest.

Received for publication: 11 September 2009. Revision received: 26 March 2010.

Accepted for publication: 31 March 2010.

This work is licensed under a Creative Commons Attribution 3.0 License (by-nc 3.0).

CC Copyright S.J. Ochatt and A. Moessner, 2010

Licensee PAGEPress, Italy

International Journal of Plant Biology 2010; 1:e8 doi:10.4081/pb.2010.e8

where, ' $a$ ' represents half the length of the cell along its longest axis and 'b' half the length of the cell at its shortest axis (Figure 1).

For each genotype, at least 250 cells were analyzed, experiments were repeated three times, and data were analyzed by one-way ANOVA $(\mathrm{P}=0.05),{ }^{12}$ with the significance of results among genotypes confirmed by LSD, and comparison of cell surfaces carried out by Student's t-test.

\section{Results}

Differences in cell shape between genotypes were apparent, and it was possible to distinguish between round and elongated cells. These, however, remain difficult to quantify. Thus, particularly for genotype Princess where the largest discrepancy was apparent between cell surface (Figure 2A) and cell volume (Figure 2B), it appeared that this could easily be explained by taking into account the elongated shape of its cells.

However, when measuring cell volume, a Coulter densitometer will assimilate all objects to a sphere and there is therefore the risk that two small cells stuck to each other might be counted as a single larger one. Conversely, when the cell surface is measured microscopically, the operator cannot assess cell depth and 


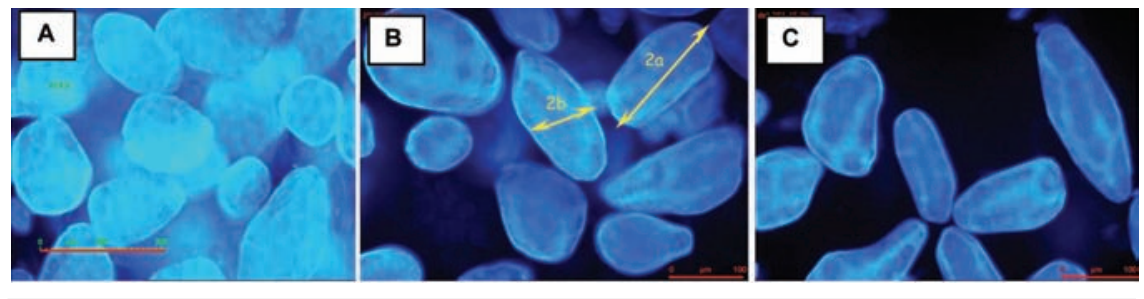

Figure 1. Typical cell shapes of genotypes D265 (A), RIL156 (B) and Princess (C). Arrows in (B) indicate the position of ' $a$ ' and ' $b$ ' used for calculation of the Shape Coefficient. Scale bars are $200 \mu \mathrm{m}$ in (A) and $100 \mu \mathrm{m}$ in (B and C).
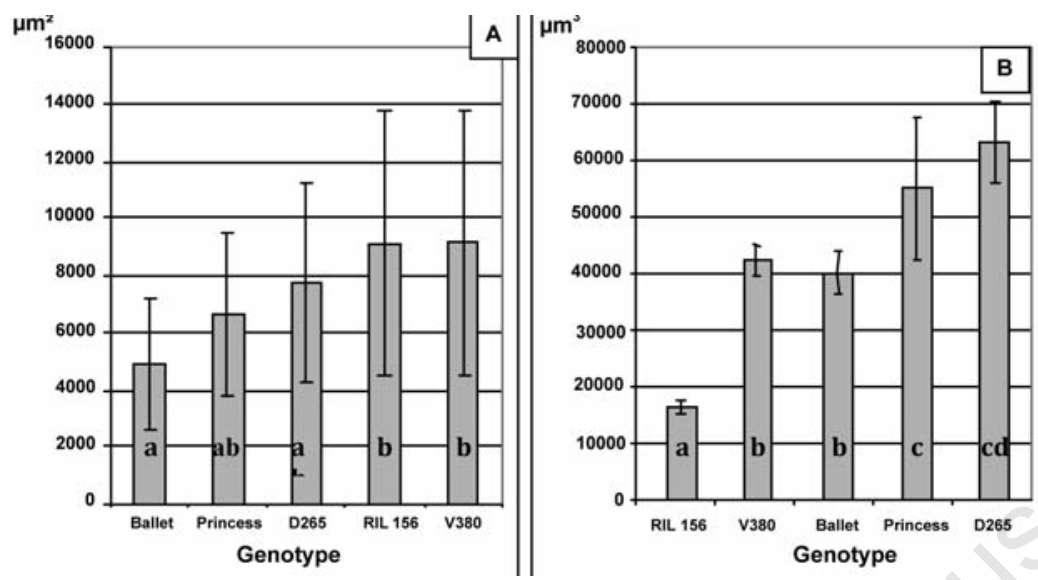

Figure 2. Surface (A) and volume (B) of cotyledonary cells of five pea genotypes. Data are expressed as the mean \pm SE. Different letters within bars indicate significant differences $(\mathbf{P}=\mathbf{0 . 0 5})$.

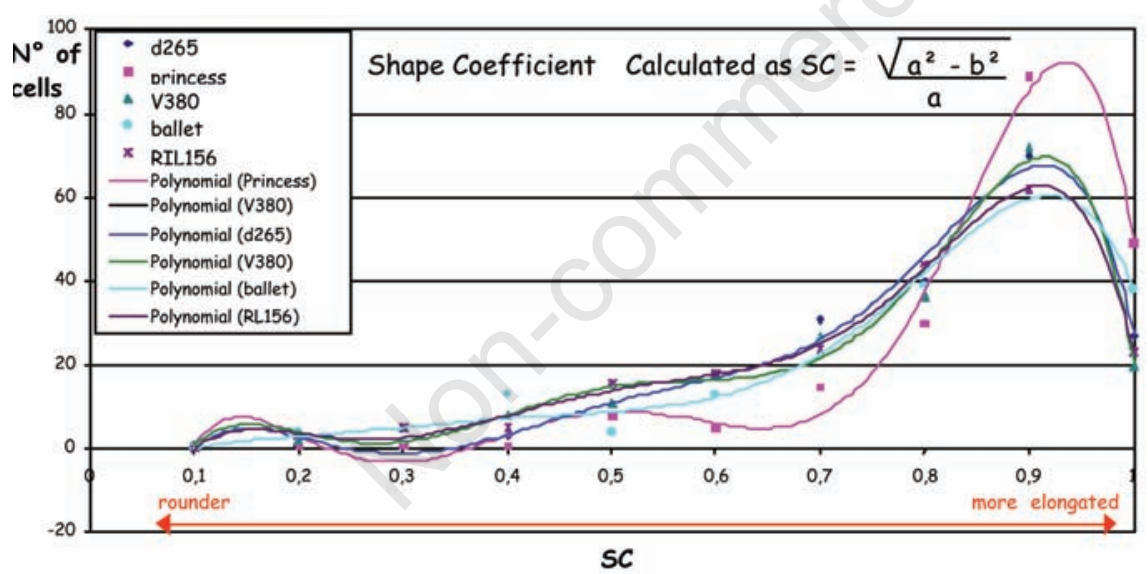

Figure 3. Shape coefficient (SC) at 0.1 intervals and polynomial regression curves for all genotypes.

this could cause bias in the data. This can explain the variability in figures for cell surface in a given genotype (Figure 1A). In addition, it is not uncommon that different cell shapes co-exist within a genotype, as shown in Figure 2.

The shape coefficient, SC, developed was able to distinguish the cell shape in all five genotypes (i.e. round versus elongated, as the $\mathrm{SC}$ value is close to 1.0 for elongated cells and lower than 0.5 for rounder ones; Figure 3).
For calculation of the polynomial curves in Figure 3, individual sections for each point in the curve were established at 0.1 intervals of the $\mathrm{SC}$, which resulted in the generic equation $\mathrm{y}=-\mathrm{x} 6+\mathrm{x} 5-\mathrm{x} 4+\mathrm{x} 3-\mathrm{x} 2+\mathrm{x}-\mathrm{c}$.

Against this background, the same five genotypes were analyzed for the morphometric parameters (cell surface, cell volume), using ground seeds. The results of mean cell volume are illustrated in Figure 4. The cell volume values obtained from intact mature seeds of the same genotypes in a previous study ${ }^{10}$ are also included as for reference $(\mathrm{H}+\mathrm{P}$ coty). It is important to state that only particles of a size coherent with that of pea cotyledonary cells (i.e. between 39.66 and $179.7 \mu \mathrm{m}$ ) were considered, in order to avoid any bias from any cell debris that might have been present in the preparations.

In general, the genotype Ballet retained its ranking irrespective of the method used for particle disaggregation in the samples. However, the genotype Princess yielded smaller cell volumes than V380, contrary to results from intact mature seed cotyledons. The most strikingly heterogeneous data were observed for the genotype D265, which had the smallest volume of cotyledonary cells in former studies, but exhibited the largest volume for particles recovered after grinding through grids of 125 and $160 \mu \mathrm{m}$ (T125 and T160), reflecting heterogeneity in particle shape. Secondly, the most reliable results are obtained when measurements are performed on samples that have been disaggregated both by hydrolysis and enzymes. It is with this treatment that results are most consistent, whatever particle size grid used to recover the ground samples. Data for genotype RIL156 are not coherent between ground and intact seeds, but when applying the SC calculated this can be explained by the heterogeneity inherent to this genotype in terms of cell shape, as it contains similar proportions of round, oval and elongated cells (cf. Figures $2 \mathrm{~B}$ and 3 ).

\section{Discussion}

Morphological diversity has the potential to provide useful biodiversity by emphasizing essential aspects of diversity that are not necessarily picked up by taxonomic or phylogenetic indices, and the comparison between different aspects of diversity is frequently essential to understand the processes underlying the patterns of biodiversity observed, ${ }^{13,14}$ for instance when describing genetic novelties such as those obtained via chemical, physical or insertional mutagenesis.

Among the most frequent problems for the microscopic and volumetric analysis of intact plant cells, shape is probably the most important and the most widely used., ${ }^{5,14}$ Since plant cells (as opposed to animal ones) are rarely spherical they are difficult to measure. This is problematic when fluorochrome signals have to be used, as is the case in flow cytometry, ${ }^{15}$ image analysis ${ }^{14}$ and cell surface ${ }^{4}$ or volume measurements. ${ }^{10}$ One solution is to produce protoplasts, i.e. cells deprived of their walls which, being spherical, will not disturb the light trajectory as irregularly-shaped objects do. ${ }^{15}$ This, however, requires a preparation that 
4. Ochatt S, Muilu R, Ribalta F. Cell morphometry and osmolarity as early indicators of the onset of embryogenesis from cell suspension cultures of grain legumes and model systems. Plant Biosyst 2008; 142:480-6.

5. Chanliaud E, Burrows KM, Jeronimidis G, Gidley MJ. Mechanical properties of primary cell wall analogues. Planta 2002;215: 989-96.

6. Kerstens S, Verbelen J-P. Cellulose orientation at the surface of Arabidopsis seedling. Implication for biomechanics in plant development. J Structural Biol 2003; 144:262-70.

7. Ambrose MJ, Wang TL, Cook SK, Hedley CL. An analysis of seed development in Pisum sativum. J Exp Bot 1987;38:1909-20.

Figure 4. Mean volume of ground particles (diam. between 39.66 and $179.7 \mu \mathrm{m}$ ) for five genotypes, three granule size classes $(125,160$ and $200 \mu \mathrm{m})$ and three treatments $(T$ [none $=$ control], $\mathrm{H}$ [hydrolysis], $\mathrm{H}+\mathrm{P}$ [hydrolysis + pectinase) per granulometry (i.e. T125, T160, T200, H125, H160, H200, H+P125, H+P160, H+P200), compared to the mean volume of cotyledonary cells $\left(\mathrm{H}+\mathrm{P}\right.$ coty) as reported in Roche et al. ${ }^{10}$ Bars of genotypes with different letters within each treatment were significantly different at $\mathbf{P}=\mathbf{0 . 0 5}$ ( $\geq 50$ and three independent experiments).

is far more difficult, long and costly than that of cells and with a composition of enzyme solutions for tissue digestion that is strongly dependent on genotype and tissue source, on developmental stage and, more importantly, that requires the use of osmotica so that isolated protoplasts will not burst. Unfortunately, such osmotic agents will also alter the original shape of cells by rendering them turgescent and concomitantly bias the results of such analyses.

Taxonomic patterns may mask other spatial patterns of morphological, functional or phylogenetic biodiversity. ${ }^{13}$ Many published articles on the nature of biodiversity set on with the recognition that the richness of a species is only one way of measuring biodiversity and, yet, proceed to treat it as if it were its whole measure. ${ }^{13,14}$ This is probably due to the relative success of different methods to measure and describe the shape of biological objects, plant cells in particular, ${ }^{8,14}$ and the lack of reliability in the classing of different species or genotypes within a species when different methods are used to assess their morphometry.

The present results show the importance of shape as an additional parameter for cell characterization, particularly for the identification of pea ideotypes better adapted as feed for either monogastrics or ruminants. More gen- erally, the shape coefficient we devised should also find use in other studies (e.g. taxonomy) and with other species, where the non-sphericity typical of plant cells might bias analyses, such as in flow cytometry ${ }^{15}$ or quantitative microfluorometric studies, ${ }^{4}$ and also for the validation of gene function of genotypes modified genetically (by insertional or chemical mutagenesis) for genes involved in embryo development and seed filling, where a reliable characterization of the cotyledonary cells in their seeds will be required.

\section{References}

1. Iqbal A, Khalil IA, Ateeq N, Khan MS. Nutritional quality of important food legumes. Food Chemistry 2006;97:331-5.

2. Lallés JP. Nutritional and antinutritional aspects of soyabean and field pea proteins used in veal calf production: a review. Livestock Production Sci 1993;34:181-202

3. Vigeolas H, Chinoy C, Zuther E, et al. Combined metabolomic and genetic approaches reveal a link between the polyamine pathway and albumin 2 in developing pea seeds. Plant Physiol 2008;146:74-82
8. Lemontey C, Mousset Déclas C, et al. Maternal genotype influences pea seed size by controlling both mitotic acitivity during early embryogenesis and final endoreduplication level/cotyledon cell size in mature seeds. J Exp Bot 2000;51:167 75.

9. Brillouet J-M, Carré B. Composition of cell walls from cotyledons of Pisum sativum, Vicia faba and Glycine max. Phytochemistry 1983;22:841-7.

10. Roche JB, Ochatt S, Moessner A, Etévé G, Duc G. Genotypic and environmental effects on the relationship between seed size, cotyledon cell volume, cell shape and cell wall thickness in protein pea. In: Vth Eur Conf Grain Legumes: Legumes for the benefit of agriculture, nutrition and the environment; 2004 June 7-11; Dijon France. p. 268.

11. Rattee ID, Breur MM. Calcofluor White. In: The Physical Chemistry of Dye Absorption, Academic Press, New York, 1974;180-2.

12. Sas Institute. SAS/STAT Guide for Personal Computer, 6th edition. 1987. SAS Institute, Cary, NC.

13. Roy K, Foote M. Morphological approaches to measuring biodiversity. Tree 1997;12: 277-81.

14. McLellan T, Endler JA. The relative success of some methods for measuring and describing the shape of some complex objects. Syst Biol 1998;47:64-81.

15. Ochatt SJ. Flow cytometry in plant breeding. Cytometry A 2008;73:581-98. 